\title{
The cultural practice of removing shoes indoors is relevant to the mortality rate of the SARS-CoV-2 pandemic.
}

Soshi Iwasaki ( $\square$ soushiiwasaki@gmail.com )

Sapporo Medical University

Kazunobu Takahashi

Sapporo Medical University

Michiaki Yamakage

Sapporo Medical University

\section{Short Report}

Keywords: COVID-19, cultural practice of removing shoes indoors, mortality

Posted Date: December 2nd, 2020

DOI: https://doi.org/10.21203/rs.3.rs-32956/v2

License: (1) (i) This work is licensed under a Creative Commons Attribution 4.0 International License.

Read Full License 


\section{Abstract}

Japan has had a lower number of SARS-CoV-2 cases than anticipated. Hence, we hypothesize that the habit of removing shoes indoors, which is practiced in various countries, might influence the SARS-CoV-2 transmission patterns and COVID-19 associated morbidity and mortality through transmission-based infection. There are significantly fewer COVID-19 deaths in countries that follow the cultural practice of removing shoes indoors.

\section{Introduction}

On January 30, the WHO Executive Director, Tedros Adhanom, declared that a novel strain of coronavirus (COVID-19) had emerged, representing a "public health emergency of international concern." The first case of infection in Europe was confirmed on January 24 in France; subsequently, COVID-19 spread rapidly throughout Europe and North America. By the end of January, airlines worldwide were suspending or reducing flights, while flights to China were being restricted as countries attempted to stop the influx of new coronavirus cases. However, Japan permitted air travel for a significant length of time. Consequently, pessimistic predictions were made, such as "Tokyo and Japan will be like New York in two weeks."

Currently, in terms of the spread of COVID-19, Japan does not resemble New York or London. Why has the spread of the virus occurred so differently in Japan? Various explanations have been offered. One theory is that the number of polymerase chain reaction tests (PCR tests) in Japan is extremely low. Another theory proposes that this is due to a difference in the coverage of the Bacillus Calmette-Guérin vaccine (BCG vaccine), a tuberculosis vaccine.(1) Based on these observations, we hypothesized that the removal of shoes indoors is relevant to the progression of the SARS-CoV-2 pandemic.

\section{Materials And Methods}

This paper utilizes Gursel's study method.(1) Currently, no study has investigated the cultural practices of removing shoes indoors in multiple countries. Therefore, information was gathered from Wikipedia.(2) To test the validity of our hypothesis, we compared the number of COVID-19 cases and deaths per million people in 35 countries in which COVID-19 cases have numbered over 15,000 (Table 1). The countries were divided into two groups: those that follow the cultural practice of removing shoes indoors and those that do not. Coronavirus-related statistics were based on data obtained from Worldometers statistics,(3) and world population statistics were taken from Current World Population data.(4) Further, statistical comparisons in this study were based on the two-tailed Mann-Whitney $U$ test.

\section{Results}

No significant correlation was found between the number of COVID-19 cases and the cultural practice of removing shoes indoors ( $U$ value $=94, z$-score $=-1.85$, p-value=0.06432; Fig. 2). However, there are significantly fewer COVID-19 deaths in countries that follow the cultural practice of removing shoes indoors ( $U$ value $=60, z$-score $=-2.98333$, $p$-value $=0.00288$; Fig. 3 ). 


\section{Conclusion}

Currently, the positive antibody rate of SARS-CoV-2 in different countries is unknown. Furthermore, the antibody's effectiveness has not been proven. PCR tests, antigen test kits, and antibodies (IgG, IgM) are used to detect infected people. PCR struggles to detect infected people before the onset of the disease, and negative results are likely to occur more than 4 weeks after the onset.(5) Approximately 2 weeks after the onset, $80 \%$ of infected people test positive for $\lg M$ or $\lg G$, and nearly $100 \%$ become positive by the following week.(6) Even with the highly reliable test kit (cobas ${ }^{\circledR} 6800$ SARS-CoV-2 Test) from Roche, the concordance rate with conventional PCR is $95.8 \%$.(7) It is controversial when and on whom such inspections should be conducted, consequently, we considered mortality to be more important than morbidity in this study. Doremalen reported that SARS-CoV-2 remained viable in aerosols throughout a 3hour experiment, and it was more stable on plastic and stainless steel than on copper and cardboard, and the virus was detected up to 72 hours after application to these surfaces.(8) Thus, the virus was found to survive on the floor of the rooms of an infected person, as reported on the Diamond Princess cruise ship.

Case numbers are dependent on the SARS-CoV-2 testing capability of each country and, thus, they might not be representative of the true extent of the epidemic. Consequently, we also compared the number of deaths per million. The results demonstrated that COVID-19-associated deaths relative to the size of the population were significantly lower in countries that follow the cultural practice of removing shoes indoors than in those that do not. This suggests that one of the reasons behind Japan's low COVID-19 death toll is the cultural practice of removing shoes indoors. Therefore, we should continue this cultural practice in Japan, and policies on handling shoes should be introduced in hospitals all over the world.

\section{Declarations}

Competing interests: The authors declare no competing interests.

\section{References}

1. Gursel M, Gursel I. Is Global BCG Vaccination Coverage Relevant To The Progression Of SARS-CoV-2 Pandemic? Med Hypotheses 2020 Apr 6. doi: https://doi.org/10.1016/j.mehy.

2. https://en.wikipedia.org/wiki/Tradition_of_removing_shoes_in_the_home_and_houses_o f_worship

3. https://worldometers.info/coronavirus/ (According to the latest update on May 11, 2020, 20:00 GMT)

4. According to the latest update on May 11, 2020, 20:00 GMT

5. Sethuraman N, Jeremiah SS, Ryo Interpreting Diagnostic Tests for SARS-CoV-2. JAMA. 2020 May 6. doi: 10.1001/jama.2020.8259.

6. Zhao J, Yuan Q, Wang H, et al. Antibody Responses to SARS-CoV-2 in Patients of Novel Coronavirus Disease Clin Infect Dis. 2020 Mar 28. doi: 10.1093/cid/ciaa344. 
7. Pujadas E, Ibeh N, Hernandez MM, et al. Comparison of SARS-CoV-2 Detection from Nasopharyngeal Swab Samples by the Roche cobas ${ }^{\circledR} 6800$ SARS-CoV-2 Test and a Laboratory-Developed Real-Time RT-PCR J Med Virol. 2020 May 8. doi: 10.1002/jmv.25988.

8. Doremalen N, Bushmaker T, Morris D, et Aerosol and Surface Stability of SARS-CoV- 2 as Compared with SARS-CoV-1. N Engl J Med. 2020 Apr 16. doi: 10.1056/NEJMc2004973

\section{Table}

Due to technical limitations, table 1 is only available as a download in the supplemental files section.

\section{Figures}

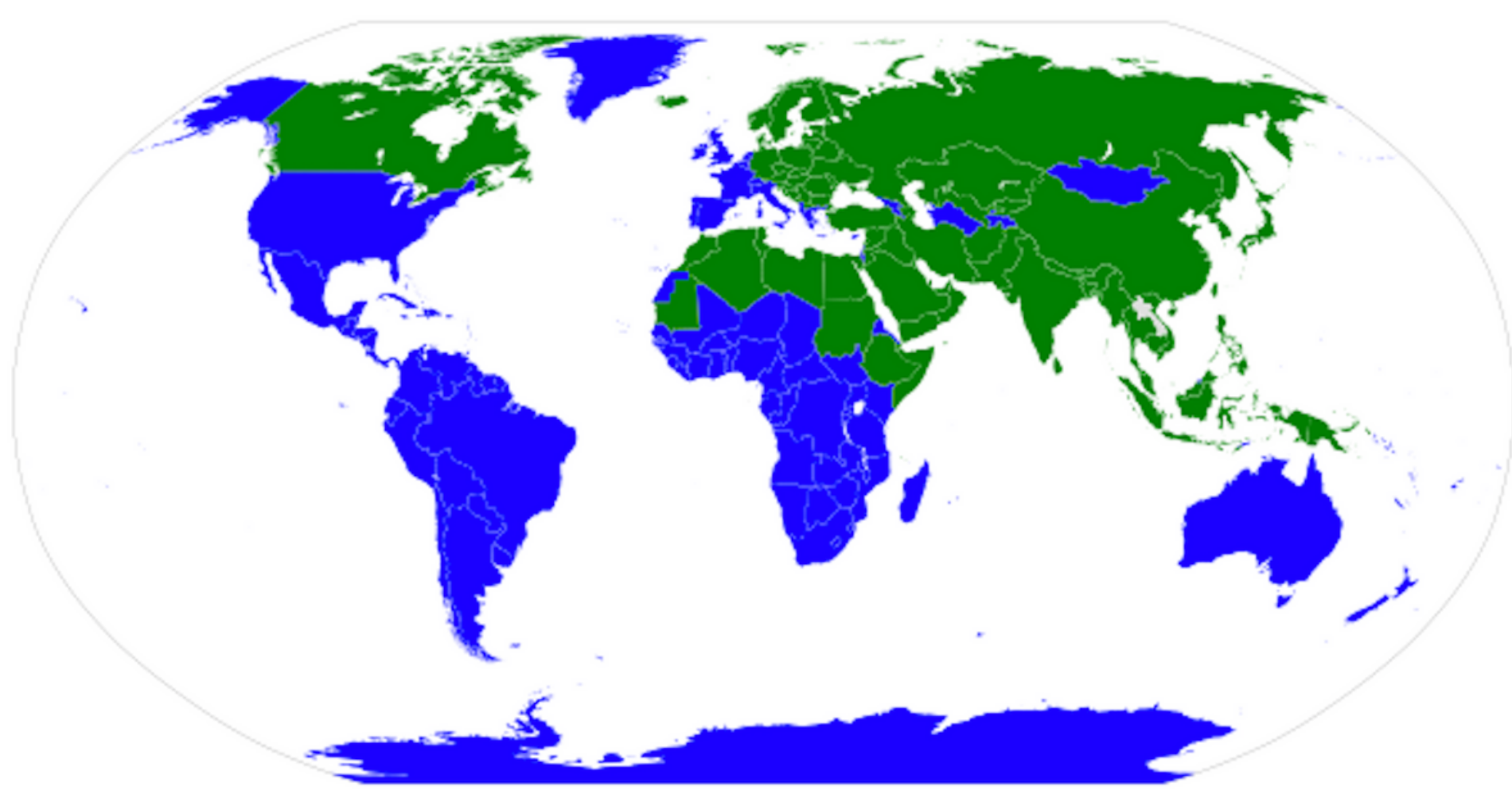

Figure 1

Countries with cultural practice of removing shoes (green) and without (blue). From Wikipedia: https://commons.wikimedia.org/wiki/File:Tradition_of_removing_shoes_in_home.svg Author: S.Orvarr. Note: The designations employed and the presentation of the material on this map do not imply the expression of any opinion whatsoever on the part of Research Square concerning the legal status of any country, territory, city or area or of its authorities, or concerning the delimitation of its frontiers or boundaries. This map has been provided by the authors. 


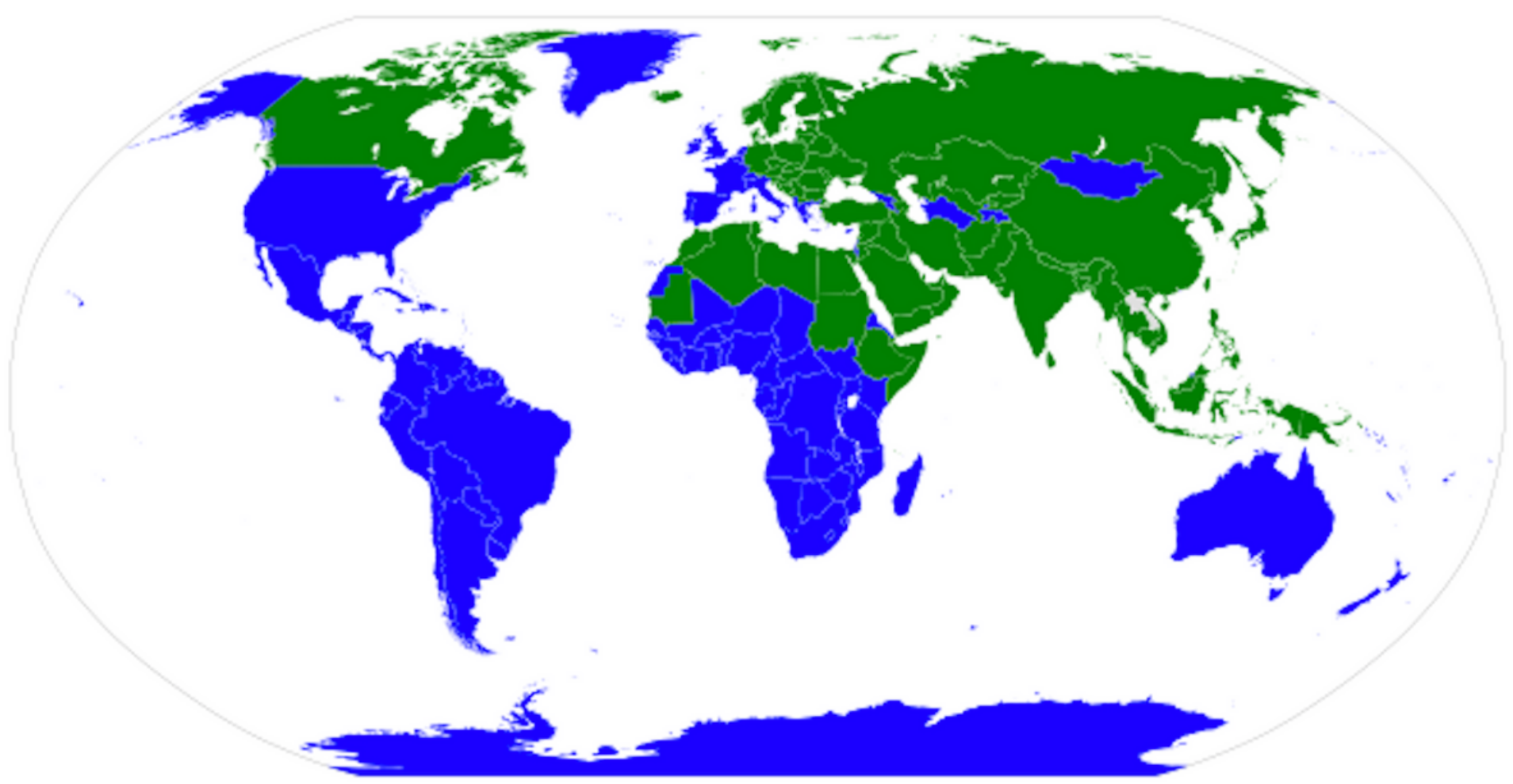

\section{Figure 1}

Countries with cultural practice of removing shoes (green) and without (blue). From Wikipedia: https://commons.wikimedia.org/wiki/File:Tradition_of_removing_shoes_in_home.svg Author: S.Orvarr. Note: The designations employed and the presentation of the material on this map do not imply the expression of any opinion whatsoever on the part of Research Square concerning the legal status of any country, territory, city or area or of its authorities, or concerning the delimitation of its frontiers or boundaries. This map has been provided by the authors. 
7000 Countries with cultural practice of removing shoes

6000
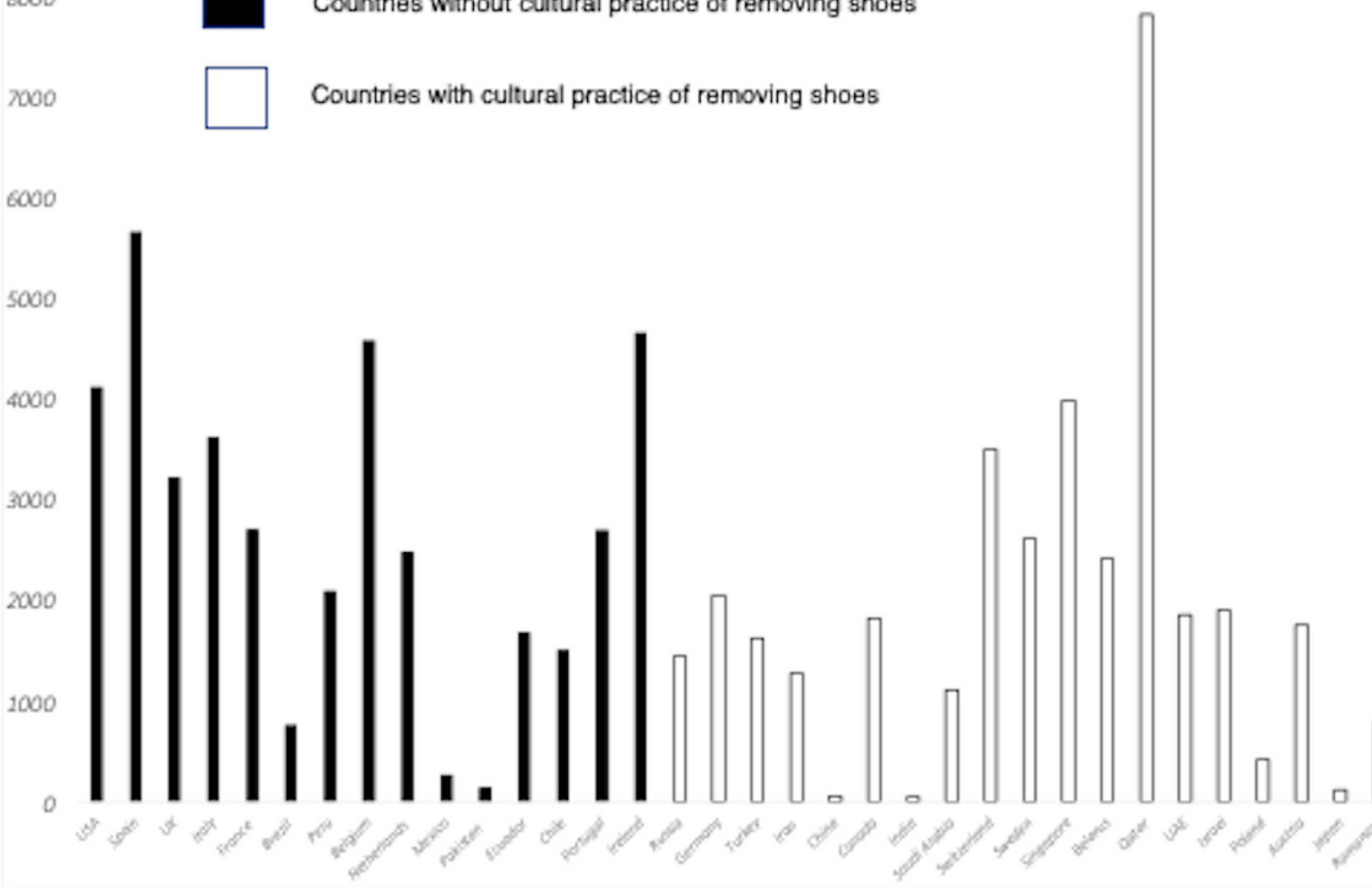

Figure 2

Cases per million. $U$ value $=94$. Z-score $=-1.85$. The $p$-value $=0.06432$ 
8000 Countries without cultural practice of removing shoes

7000 Countries with cultural practice of removing shoes

6000
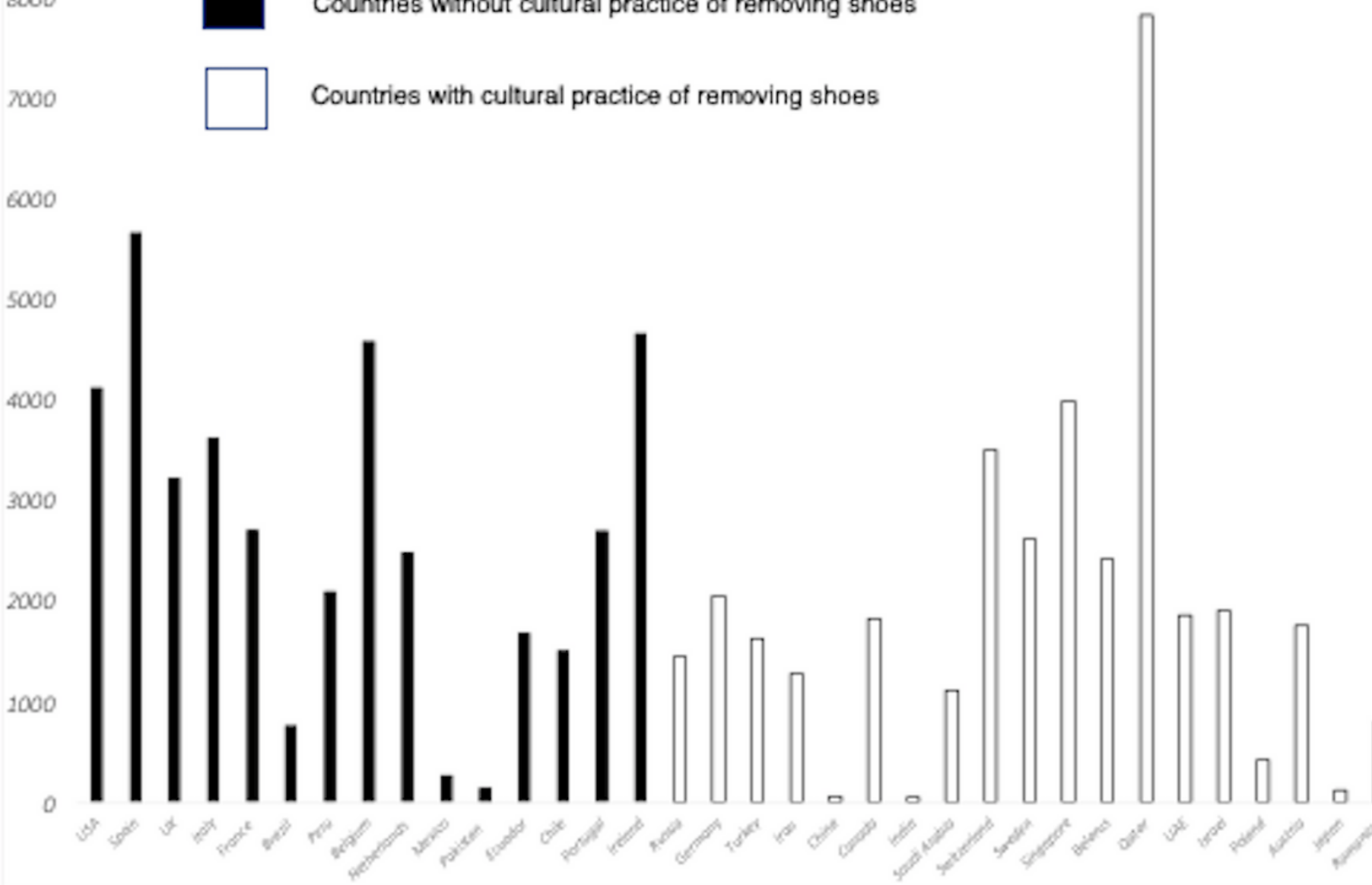

Figure 2

Cases per million. $U$ value $=94$. Z-score $=-1.85$. The $p$-value $=0.06432$ 


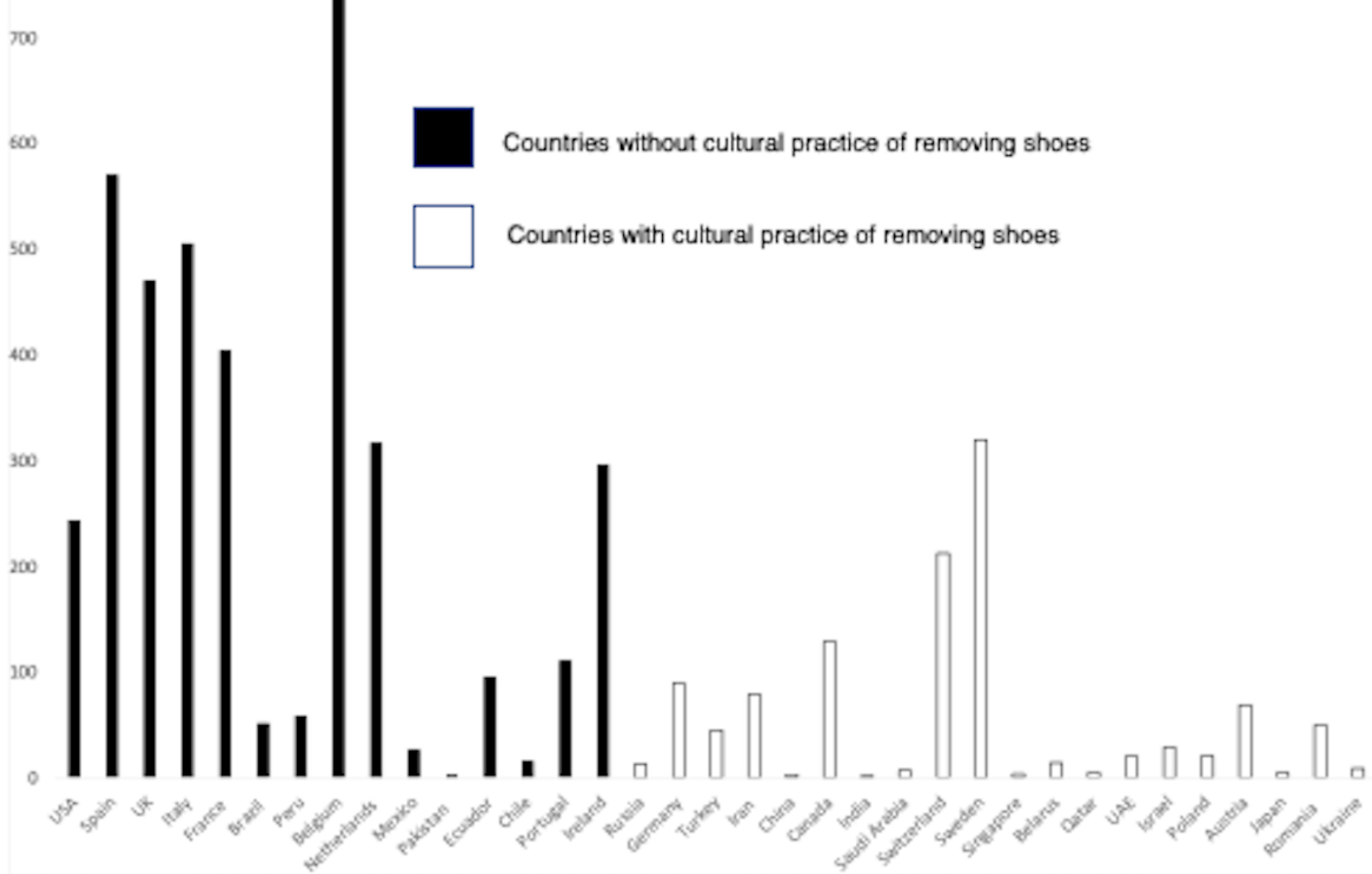

Figure 3

Deaths per million. $U$ value $=60 . Z$-score $=-2.98333$. The $p$-value $=0.00288$ 
$6 \infty$

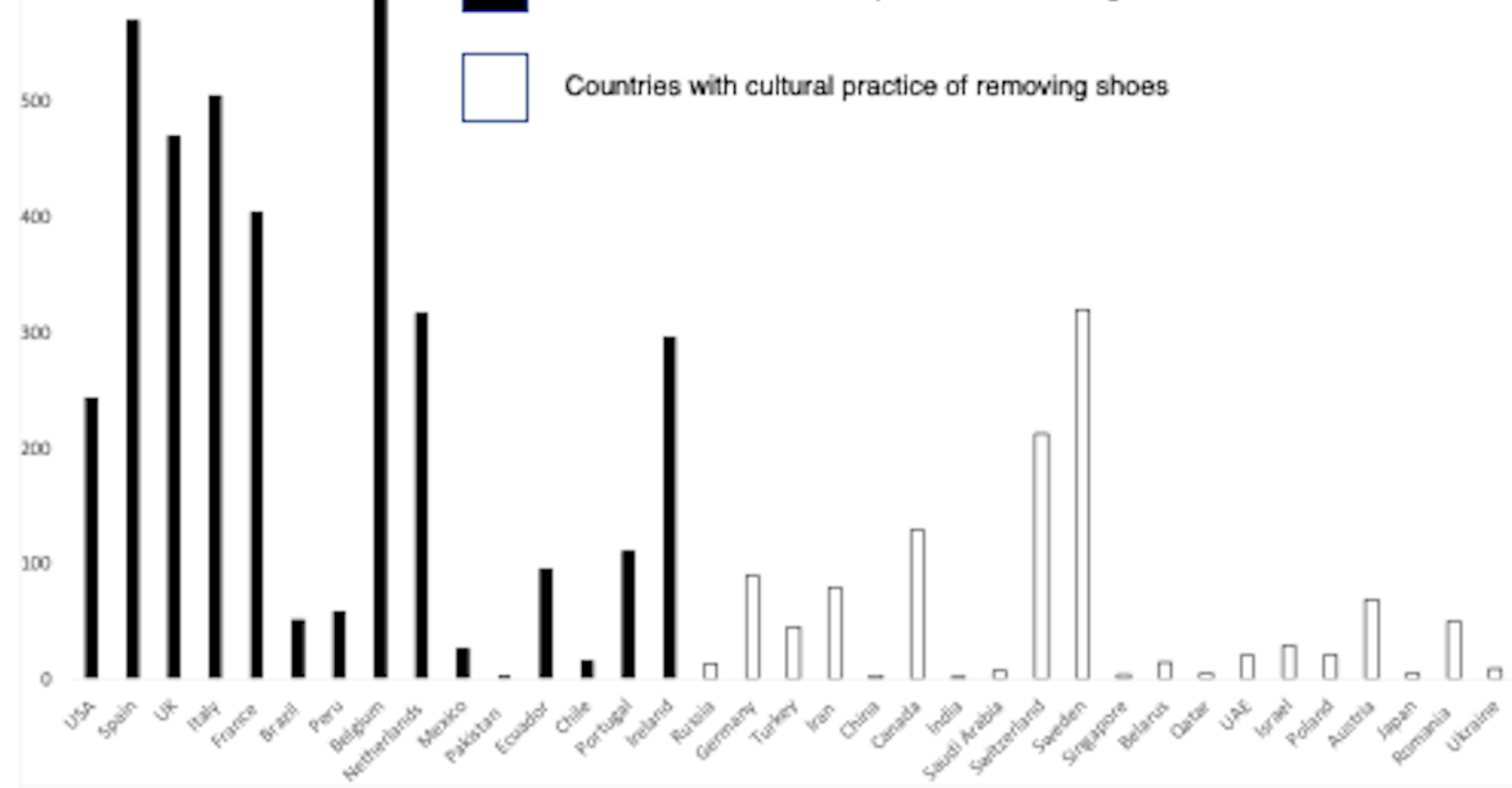

Figure 3

Deaths per million. $U$ value $=60 . Z$-score $=-2.98333$. The $p$-value $=0.00288$

\section{Supplementary Files}

This is a list of supplementary files associated with this preprint. Click to download.

- 1.png

- 1.png 